\title{
Comparison of the Effectiveness of Cognitive Behavioral Therapy and Acceptance and Commitment Therapy on Reducing Mood Symptoms in Patients With Substance Abuse
}

\author{
Sara Haghighat ${ }^{1}$, Alireza Mohammadi ${ }^{*}$ \\ 'Islamic Azad University, Garmsar Branch, Garmsar, Iran
}

\begin{abstract}
Background: The purpose of this study was to compare the effectiveness of cognitive-behavioral therapy (CBT) and acceptance and commitment therapy (ACT) on reducing mood symptoms in patients with substance abuse.

Methods: The current research was a semi-experimental study with pre-test and post-test with a control group. The participants consisted of all people with substance abuse referred to drug abuse treatment centers in district 4 and 8 of Tehran city in 2016-2017. In this way, 45 subjects selected by purposeful sampling method and randomly divided into 2 groups of experimental and one control group (15 persons for each group). Then, the Mood Disorder Questionnaire and Depression Inventory took from the subjects of each group. CBT and ACT performed in 8 sessions of 90 minutes in 2 experimental groups and control group were also without any training program. After completing the training, the post-test performed for all three groups. Data analysis was done by using the covariance analysis (MANCOVA) and using SPSS-21 software.

Results: The findings showed that $\mathrm{CBT}$ and $\mathrm{ACT}$ were effective in reducing mood syndrome in patients with substance abuse $(\mathrm{P}<00.001)$. Moreover, there were no significant differences between the effectiveness of the CBT and ACT on the reduction of mood syndrome in patients with substance abuse.

Conclusion: Considering the effect of $\mathrm{CBT}$ and $\mathrm{ACT}$ on the reduction of mood syndrome among patients with substance abuse, it is worth considering the role of these 2 treatments as one of the educational and therapeutic strategies for substance abuse.

Keywords: Cognitive behavioral therapy, Acceptance and commitment therapy, Mood syndrome, Substance abuse
\end{abstract}

Citation: Haghighat S, Mohammadi A. Comparison of the effectiveness of cognitive behavioral therapy and acceptance and commitmen therapy on reducing mood symptoms in patients with substance abuse. Int Clin Neurosci J. 2018;5(4):158-163. doi:10.15171/ icnj.2018.27.

\author{
*Correspondence to \\ Alireza Mohammadi, MA in \\ General Psychology, Islamic \\ Azad University, Garmsar \\ Branch, Garmsar, Iran. Email: \\ mohammadia1366777@gmail. \\ com
}

Published online 20 December 2018

\section{Introduction}

Today, one of the critical problems of human societies, such as Iran, is the addiction problem, which endangers the health of the community, the family and the individual and disrupts the individual, occupational, family and social functions. ${ }^{1}$ The first major national study in Iran, conducted by the Ministry of Health and Medical Education in cooperation with the Office for the Prevention of Crime and the Control of Materials and the United Nations, number of opium and heroin-addicted persons has estimated 3.67. ${ }^{2}$ Taremian et al have reported $16.3 \%$ among art students $8.85 \%$ among humanistic sciences students $6 \%$ among engineering students and $5.1 \%$ among medical students as addicted. ${ }^{3}$ Dependency on drugs is the chronic and recrudescent disorder that affects genetic mental social and environmental factors. The multidimensionality of the etiology of substance use disorder and the problem of comorbidity with other disorders, including the problematic barriers to the treatment of substance use patients, so that Hasin et al showed that more than $70 \%$ addicted persons have some disorders such as personality disorders, sexual dysfunction, anxiety, depression, and physical disorders. Mood disorders and depression are among the most common disorders with addiction..$^{4-6}$ Depression leads to significant disability in individual, social life dimensions and affects a person's daily performances like eating, sleeping, and health. ${ }^{7,8}$ Depression may be a sign of the addict's haplessness, which is a barrier to effective behavior in combating addiction or exploiting coping resources in substance abusers. The prevalence of major depressive disorder in these individuals is about $50 \%$ $60 \%$, and the degree of minor depression is close to $10 \%{ }^{9}$

Bipolar disorder is a chronic psychiatry illness that

(C) 2018 The Author(s). This is an open access article distributed under the terms of the Creative Commons Attribution License (http:// creativecommons.org/licenses/by/4.0/), which permits unrestricted use, distribution, and reproduction in any medium, provided the original work is properly cited. 
patient experiences severe mood fluctuations as periods of depression and mania. Although, the annual incidence of this disorder is estimated to be about $1 \%$, nevertheless, the careful interview of many patients who receive a diagnosis of depression reveals periods of mania or hypomania in the past that it has not diagnosed. ${ }^{10}$ The rate of suicide, drug using unemployment, criminal behaviors and divorce are high in bipolar patients. These patients are more disable in comparison with normal persons. ${ }^{11}$ According to studies $46 \%$ of bipolar patients showed alcohol abusing criterions (15\%) or dependency to alcohol (31\%), 41\% bipolar patients have other drug abusing criterions (13\%) or dependency to the other drugs (28\%) and totally $61 \%$ showed abusing or dependency to drug. ${ }^{12}$

Cognitive behavioral therapy is the most important therapy among psychological therapies for improving the mood symptoms of addicted people. Depression cognitivebehavioral approach emphasizes upon individual opinion about self and his/her world. Based on cognitive behavioral therapy, individual's experiences lead to the creating schemas about self and world, that these schemes influence the perceptual organization, controlling and behavior appraisal 9.6 lead to depression. ${ }^{13}$ In this treatment, the therapist tries to abandon cognitive inconsistency from the patient and uses some behavioral methods like depriving attention and problem-solving. This therapy seeks to improve awareness and understanding of one's position and performance. Also, cognitive-behavioral therapy (CBT) results in dependency increasing to drug therapy. According to studies, patient cognitive style interaction with stressful events may predict depression semiology. Therefore CBT is effective upon depression symptoms improving. ${ }^{14}$ Many studies have examined the effectiveness of CBT on depression and bipolar disorder. Khaledian et al study on the efficacy of cognitive behavioral group therapy on reducing depression and increasing life expectancy in the empty nest syndrome found that CBT showed that cognitive behavioral group therapy is effective in reducing depression. ${ }^{1}$ Rashedi et al reported the effectiveness of this treatment in preventing recurrence of bipolar disorder. ${ }^{15}$ Ranjbar et al found that cognitive-behavioral group therapy is effective upon depression decreasing among dysthymia persons. ${ }^{16}$

Acceptance and commitment therapy (ACT) initially originated from philosophy and is based on the mental relationship theory. This therapy consists of six processes acceptance, intercept, self as the field, relation with present time, worths and commitment. ${ }^{17}$ In this treatment, the stages of this therapy are (1) Having mental acceptance about mental experiences, (2) Improving person mental knowledge from present time, (3) Teaching client to leave these experiences, (4) Decreasing concentration upon self-imagination, (5) Illuminating person worths for themselves, and (6) Creating motivation to show commitment toward worth's applied to the person. ${ }^{18}$ The researches have reported satisfactory effectiveness of the
ACT based on clinical experiences related to mood and anxiety disorders. ${ }^{19}$ Moradi et al showed that the ACT is effective in reducing depression. ${ }^{20}$ Due to the high prevalence of substance abuse among the population, especially young people, It can help to better understand this phenomenon by identifying effective factors in it, such as mood disorders (depression and bipolar disorder). Also, there is little research on this subject epically in Iran. Therefore this research can help to better understanding of this phenomenon. This research aimed to compare the effectiveness of CBT and ACT on reducing mood symptoms in patients with substance abuse.

\section{Methods}

The current research was a semi-experimental study with pre-test and post-test with a control group. The statistical population consisted of all people with substance abuse (300) referred to drug abuse treatment centers in district 4 and 8 of Tehran city in 2016-2017. In this way, 45 subjects by purposeful sampling method were selected and randomly divided into 2 groups of an experimental and control group (15 persons for each group). Then Mood Disorder Questionnaire and depression inventory were taken from the subjects of each group (pre-test). CBT (Table 1) and ACT (Table 2) therapy performed in 8 sessions of 90 minutes in 2 experimental groups and control group were also without any training program. After completing the training, the post-test performed for all three groups. Inclusion criteria consisted of: having substance abuse, identifying mood disorders by Beck depression questionnaire and bipolar disorders questionnaire, having informed satisfaction and exclusion criteria included: showing one of the severe physical illness, serious neurological disorders, before attendance in the similar interventional program and being absent more than 2 sessions. Date gathered by using the Beck depression questionnaire and mood disorder questionnaire. Data analysis was done by using the covariance analysis (MANCOVA) and using SPSS-21 software.

\section{Beck Depression Questionnaire}

This questionnaire is the best instrument to show depression states it consists of 21 items that measure physical behavioral and cognitive of depression each item has four options (with scoring 0-3). The total score is 63, and the least score is 0.21 items of Beck questionnaire classified in three groups, affective symptoms, cognitive symptoms, and physical symptoms that each of them contains eight questions. ${ }^{21}$ Meta-analysis results showed 0.90 and 0.89 internal consistency coefficients and retested coefficient $0.94 .^{22}$ Van Voorhis et al reported Cronbach's coefficient $0.90 .^{23}$

Mood Disorders Questionnaire

This questionnaire has been designed by Hirschfield 
Table 1. Contents of Cognitive Behavioral Therapy Sessions

\begin{tabular}{ll}
\hline Session & Subject \\
\hline Session 1 & Sessions structure, number, each session duration, duties and the necessity of their executing \\
Session 2 & Reviewing the first session, classifying beliefs, giving duty for next session \\
Session 3 & Reviewing previous session duty, teaching arrowhead, giving session duty \\
Session 4 & Reviewing the previous session, continuing arrowhead teaching, talking shout kinds of beliefs, sorting them giving duties \\
Session 5 & The main list of beliefs, cognitive designs, giving duty \\
Session 6 & Surveying previous session duty believes are changeable \\
Session 7 & Reviewing previous sessions duty, teaching saying no skill \\
Session 8 & Reviewing previous sessions subjects and receiving participants opinions about taught \\
\hline
\end{tabular}

Table 2. Contents of Acceptance and Commitment Therapy Sessions

\begin{tabular}{|c|c|}
\hline Session & Subject \\
\hline Session 1 & $\begin{array}{l}\text { Introducing addiction illness and its symptoms, therapy method, discussion about confidence, the client informed satisfaction to } \\
\text { finish therapy Process, total appraisal, determining client wanting from therapy, acquaintance with creative hopelessness concept }\end{array}$ \\
\hline Session 2 & Surveying previous session reflection upon person life, talking about creative hopelessness, substance abuse \\
\hline Session 3 & $\begin{array}{l}\text { Surveying previous session reflection upon person life, surveying homework's, introducing control as one problem not solving the } \\
\text { problem, acquaintance with the desire-acceptance concept, giving homework's }\end{array}$ \\
\hline Session 4 & $\begin{array}{l}\text { Surveying person experiences from the previous session until now surveying homework's and behavioral commitments, } \\
\text { acquaintance with self-concept as field }\end{array}$ \\
\hline Session 5 & $\begin{array}{l}\text { Surveying person experiences from the previous session until now, surveying homework's, acquaintance with cognitive diffusion } \\
\text { concept, giving homework's }\end{array}$ \\
\hline Session 6 & $\begin{array}{l}\text { Surveying previous session reflection upon a person's life, surveying acceptance and commitment homework's control method in } \\
\text { substance abuse }\end{array}$ \\
\hline Session 7 & Acquaintance with worths concept, illustrating worths in different fields, giving homework's \\
\hline Session 8 & $\begin{array}{l}\text { Surveying clients experiences from therapy beginning until now, surveying discussions, reviewing homework's, discussion about } \\
\text { behavioral commitments }\end{array}$ \\
\hline
\end{tabular}

et al to identify bipolar disorders. This questionnaire consists of 3 sections. The first section has consisted of 13 questions that screen patients by mania or hypomania symptoms. The second section of this questionnaire identifies mania or hypomania symptoms with yes/no simultaneously and finally the third section surveys the level of existed disorder in total performance. More than 6 positive responses to the first 13 questions show bipolar disorder and the last 2 questions show symptoms severity and social performance disorder rate. The validity and reliability of this instrument have been reported by Hirschfield et al 0.73 and 0.90 , respectively. ${ }^{24}$ Also Cronbach a was 0.76 for the first 13 questions and 0.81 for 15 questions. High sensitivity MDQ to identify bipolar disorders results in easy screening. ${ }^{25}$

\section{Results}

In the demographic variable section, gender, age, and educational status of subjects were examined (Table 3 ). Most of the subjects were male, aged between 31 and 40 and graduated.

The mean and standard deviation, the minimum and maximum score of depression and bipolar disorders have shown at Table 4. According to Table 4, the mean of depression score for CBT group at pretest stage was 35.40 and 21.20 for post-test and ACT group at pretest was 33.66 and 22.20 for post-test. Also, bipolar disorders score for CBT group at pretest stage was 9.86 and 6.85 for posttest and ACT group at pre-test was 10.33 and 6.13 at post-test. The other results are observable at Table 4 .

It was used covariance analysis to study the effectiveness of CBT and ACT upon mood disorders (Table 5). Multivariate covariance analysis test results show significant differences at least for one of the dependent variables (depression \& bipolar disorder) $(P=0.001)$ (Table 5).

It was used ANCOVA analysis to survey this difference (Table 6).

Table 3. Frequency Distribution of Subjects in Terms of Demographic Variables

\begin{tabular}{llc}
\hline Variable & & No. (\%) \\
\hline \multirow{2}{*}{ Gender } & Male & $27(60)$ \\
& Female & $18(40)$ \\
\multirow{2}{*}{ Age } & $20-30$ & $15(33.33)$ \\
& $31-40$ & $22(48.88)$ \\
& $41-50$ & $8(17.77)$ \\
Educational status & Diploma & $22(48.9)$ \\
& Associate degree & $11(24.4)$ \\
& Bachelor of art & $9(20)$ \\
& Master of art & $3(6.7)$ \\
\hline
\end{tabular}


Table 4. Mean (Standard Deviation), Minimum and Maximum of Depression and Bipolar Disorders Scores for Subjects

\begin{tabular}{|c|c|c|c|c|c|}
\hline Variables & & Group & Mean (SD) & Min. & Max. \\
\hline \multirow{6}{*}{ Depression } & \multirow{3}{*}{ Pre-test } & CBT & $35.40(3.06)$ & 23 & 45 \\
\hline & & $\mathrm{ACT}$ & $33.66(3.03)$ & 22 & 46 \\
\hline & & Control & $32.86(2.14)$ & 23 & 44 \\
\hline & \multirow{3}{*}{ Post-test } & CBT & $21.20(8.27)$ & 16 & 24 \\
\hline & & ACT & $22.20(7.45)$ & 18 & 25 \\
\hline & & Control & $32.13(2.89)$ & 23 & 45 \\
\hline \multirow{6}{*}{$\begin{array}{l}\text { Bipolar } \\
\text { disorder }\end{array}$} & \multirow{3}{*}{ Pre-test } & CBT & $9.86(1.55)$ & 8 & 11 \\
\hline & & ACT & $10.33(1.40)$ & 9 & 12 \\
\hline & & Control & $10.46(0.35)$ & 7 & 11 \\
\hline & \multirow{3}{*}{ Post-test } & $\mathrm{CBT}$ & $6.85(2.94)$ & 6 & 8 \\
\hline & & ACT & $6.13(2.54)$ & 6 & 7 \\
\hline & & Control & $10.40(2.19)$ & 7 & 11 \\
\hline
\end{tabular}

According to means and significance level, there is a significant difference between experimental and control group scores for depression variable $(\mathrm{F}=17.53, \mathrm{p}<0.001)$ and bipolar disorder $(\mathrm{F}=16.28, \mathrm{p}<0.001)$. This result indicates that CBT and ACT are effective upon mood symptoms decreasing (depression and bipolar disorder) (Table 6).

It was used Duncan test to determine the difference of mood disorders (depression and bipolar disorder among three groups (CBT \& ACT and control) the findings showed that there was no significant difference between $\mathrm{CBT}$ and ACT on reducing depression symptoms $(\mathrm{P}>0.05)$ but difference between the 2 groups with the control group was significant $(\mathrm{P}<0.05)$. Also, in the case of bipolar disorder, the results showed that mean of CBT and ACT are equal $(\mathrm{P}>0.05)$, but the mean of these 2 groups was significantly different with the mean of the control group $(\mathrm{P}<0.05)$. Therefore, we can conclude that these 2 therapies are equal upon patients with bipolar disorder symptoms improving.

\section{Discussion}

The purpose of this study was to compare the effectiveness of CBT and ACT on reducing mood syndrome in patients with substance abuse. According to results, CBT is effective upon mood syndrome improvement. This finding is inconsistent with many studies results. ${ }^{26-32}$ Depressed person thinking system consists of negative thoughts about self, present experience and future. Negative thoughts about self-believe too, and therefore he/she does not satisfy (addict thinks that he/she will not have enough abilities to deal with the difficulties of leaving the drug). Negative thoughts of the depressed person about experience consist of interpretations about events. He/she knows negative impedimenta as unsolvable, even when there are more positive attitudes about his experience (For example, if one attempt has failed for withdrawal, despite the apparent reasons for failure, he considers withdrawal is impossible and makes any effort useless). He tends to be the worst possible interpretation of what has happened to him. Finally, helpless attitude is the negative attitude of the depressed person about the future. When he thinks of the future, he/she believes that the negative events that have already happened to him will continue to be due to his personal deficiencies in the future. Cognitivebehavioral techniques by challenging negative thoughts and reinforcing strategies to reach the goal help to reduce depression. ${ }^{1}$

CBT in depression emphasizes a negative tendency in the information process that results from the distortion of interpretations of itself about the environment and the future. Cognitive behavioral techniques are also very effective in reducing restlessness, disturbances and impulsive behaviors. ${ }^{15}$ Impulsive behavior can create a dangerous situation for these patients that is not conscious and having extreme thoughts and impulses can lead to self-harmful behaviors, inappropriate behavior with others, and immediate impulses and inappropriate

Table 5. Multivariate Analysis Results to Study the Effectiveness of CBT and ACT Upon Subjects Mood Disorders

\begin{tabular}{llllll}
\hline Test & Value & $\boldsymbol{f}$ & $\boldsymbol{d f}$ & df Error & Effect Size \\
\hline Pillai's trace & 0.583 & 7.34 & 4 & 21 & 0.58 \\
Wilks lambda & 0.417 & 7.34 & 4 & 21 & 0.001 \\
Hotelling trace & 1.39 & 7.34 & 4 & 21 & 0.001 \\
Roys largest root & 1.39 & 7.34 & 4 & 21 & 0.58 \\
\hline
\end{tabular}

Table 6. ANCOVA Results Upon Depression and Bipolar Disorder Pretest Posttest Scores Mean for the Experimental and Control Groups

\begin{tabular}{llllllll}
\hline Source & Variable & Sum Squares & df & Mean Squares & F & P Value & Eta \\
\hline \multirow{2}{*}{ Group } & Depression & 1313.66 & 2 & 656.83 & 17.53 & 0.001 & 0.467 \\
& Bipolar disorder & 203.24 & 2 & 101.62 & & 0.001 \\
\multirow{2}{*}{ Error } & Depression & 1498.18 & 40 & 374.45 & & \\
\multirow{2}{*}{ Total } & Bipolar disorder & 249.55 & 40 & 6.23 & \\
& Depression & 31477.00 & 45 & & \\
\hline
\end{tabular}


actions. In cognitive therapy, these thoughts and impulses are discussed and talk about the problems caused by these thoughts and behavior. In fact, in this treatment, the addict tries to find out more about his thoughts, attitudes, and beliefs. It should teach that these attitudes and beliefs will lead to inappropriate behaviors. Therefore, changing these attitudes will result in better functioning and appropriate behavior in individuals.

Also, the results of this study showed that admission and commitment therapy is effective in improving mood syndrome in patients with substance abuse. The present research results also showed that ACT is effective upon mood symptoms improvement among substance abusers. This finding is inconsistent with the results of Pleger et al, ${ }^{33}$ Twohig et al, ${ }^{34}$ Moharrami ${ }^{35}$ and Hor et al. ${ }^{36}$ We can state that the main purpose of ACT is mental flexibility, i.e., creating choice ability among different chooses that is more suitable, It is only possible to practice or to be imposed on the person to avoid the thoughts, emotions, memories or disturbing tendencies. ${ }^{35}$ ACT encourages referents to self-assess themselves as simple thoughts and is trained to correct negative evaluations. Also, this therapy may result in accept client thoughts, feelings, emotions and impulses. Also, cognitive blend among depressed persons is reduced by acceptance and results in decrease their cognitive dysfunctions and rationalizations. Following valuable purposes and commitment may result in reducing their psychological fraught. ${ }^{36}$ In general, it could say that ACT effectiveness upon mood syndrome improvement among substance abusers have accepted to several reasons. Some of these reasons are: this therapy changes mood, anxiety and physical disorders into psychological flexibility. Second, the client feels changing in the therapy process like reducing experimental avoidance with related believes about problems. Third, although this therapy purpose is not the reduction of disorder symptoms like depression, obsession, and anxiety, clients experience little disturbance at the final stage of therapy and show noticeable changes in depression, anxiety and the other related scales with disturbance.

\section{Conclusion}

In general, it can be concluded that, the findings of the study indicated the CBT and ACT on the reduction of mood syndrome among patients with substance abuse were effective. It is worth considering the role of these 2 treatments as one of the educational and therapeutic strategies for substance abuse.

\section{Conflict of Interest Disclosures}

The authors declare that they have no conflict of interests.

\section{Ethical Statement}

All ethical principles were considered in this article. The participants were informed about the purpose of the research and its implementation stages and signed the informed consent; they were also assured about the confidentiality of their information;
Moreover, they were allowed to leave the study whenever they wish, and if desired, the results of the research would be available to them.

\section{References}

1. Khaledian M, Kamarzarin $H$, Jalalian A. Effectiveness of cognitive-behavioral group therapy on depression in addicted people. Quarterly Journal of Research on Addiction. 2014;8(29):78-88. [Persian]

2. Mohammadi AR. Comparison of two methods of cognitive behavior therapy (CBT) and Acceptance and Commitment Therapy (ACT) on reducing mood symptoms in patients with substance abusers [Thesis]. Garmsar: Islamic Azad University of Garmsar; 2017. [Persian]

3. Taremian F, Bolhari J, Pairavi H, Ghazi Tabatabaeii M. The prevalence of drug abuse among university students in Tehran. Iran J Psychiatry Clin Psychol. 2008;13(4):335-42. [Persian]

4. Yazdi-Ravandi S, Taslimi Z, Shamsaei F, Ghaleiha A, Salemi Shakoori S, Nikkhah A. Knowledge and attitudes toward AIDS among students of Hamadan University of Medical Sciences, 2015: Comparison between medicine, nursing and paramedical Faculty. Pajouhan Scientific Journal. 2015;14(1):22-9.

5. Hasin D, Liu X, Nunes E, McCloud S, Samet S, Endicott J. Effects of major depression on remission and relapse of substance dependence. Arch Gen Psychiatry. 2002;59(4):37580.

6. Alafchi B, Yazdi-Ravandi S, Najafi-Vosough R, Ghaleiha A, Sadeghifar M. Forecasting new cases of bipolar disorder using Poisson Hidden Markov Model. Int Clin Neurosci J. 2018;5(1):7-10. doi:10.15171/icnj.2018.03

7. Rezaei T, Yazdi-Ravandi S, Ghaleiha A, Seif Rabiei MA. Depression among medical students of Hamadan University of Medical Sciences in 2014: The Role of demographic variables. Pajouhan Scientific Journal. 2015;13(4):1-8. [Persian]

8. Amini P, Ghaleiha A, Zarean E, Sadeghifar M, Ghaffari ME, Taslimi Z, et al. Modelling the frequency of depression using holt-winters exponential smoothing method. J Clin Diagn Res. 2018;12(10):24-7.

9. Yaghobi Asgharabad E, Bassak Nejad S, Mehrabi Zadeh Honarmand M, Zamiri Nejad S. Effectiveness of metacognitive therapy (MCT) on depressed addicts under methadone Maintenance treatment (MMT) in city Mashhad of Iran. Journal of North Khorasan University of Medical Sciences. 2013;5(1):167-75. [Persian]

10. Sadock BJ, Sadock VA, Ruiz P. Kaplan and Sadock's Synopsis of Psychiatry: Behavioral Sciences/Clinical Psychiatry. 11th ed. New York: LWW Wolters Kluwer; 2014.

11. Russell SJ, Browne JL. Staying well with bipolar disorder. Aust N Z J Psychiatry. 2005;39(3):187-93. doi: 10.1080/j.14401614.2005.01542.x.

12. Edalati N. Comparison of executive functions in bipolar patient with or without comorbid substance dependency (MSc Thesis). Tehran: Allameh Tabataba'i University; 2013. [Persian]

13. Robertson D. The Philosophy of Cognitive-Behavioural Therapy (CBT): Stoic Philosophy as Rational and Cognitive Psychotherapy. London: Karnac Books; 2010.

14. Patelis-Siotis I. Cognitive-behavioral therapy: applications for the management of bipolar disorder. Bipolar Disord. 2001;3(1):1-10.

15. Rashedi E, Sohrabi F, Shams J. A study of the efficacy of cognitive behavior therapy in relapse prevention of bipolar disorder. Clinical Psychology \& Personality. 2012; 3(5):49-64. [Persian] 
16. Ranjbar F, Ashkar Torab T, Dadgari A. Effect of cognitivebehavioral Group therapy on depression. Journal of Shahid Sadoughi University of Medical Sciences. 2010;18(4):299306. [Persian]

17. Hayes SC, Luoma JB, Bond FW, Masuda A, Lillis J. Acceptance and commitment therapy: model, processes and outcomes. Behav Res Ther. 2006;44(1):1-25. doi: 10.1016/j. brat.2005.06.006.

18. Rajabi S, Yazdkhasti F. The Effectiveness of Acceptance and Commitment Group Therapy on anxiety and depression in women with multiple sclerosis who were referred to the MS association. Journal of Clinical Psychology. 2014;6(1):29-38. [Persian]

19. Forman EM, Herbert JD, Moitra E, Yeomans PD, Geller PA. A randomized controlled effectiveness trial of acceptance and commitment therapy and cognitive therapy for anxiety and depression. Behav Modif. 2007;31(6):772-99. doi: 10.1177/0145445507302202.

20. Moradi O, Khaledi K. The effectiveness of Acceptance and Commitment Therapy (ACT) on depression symptoms in diabetic patients at Sanandaj diabetes clinic. The first National Conference on Sustainable Development in Educational Sciences and Psychology, Social and Cultural Studies; 2014. [Persian]

21. Beck AT, Ward $\mathrm{CH}$, Mendelson M, Mock J, Erbaugh J. An inventory for measuring depression. Arch Gen Psychiatry. 1961;4:561-71.

22. Kapci EG, Uslu R, Turkcapar H, Karaoglan A. Beck Depression Inventory II: evaluation of the psychometric properties and cut-off points in a Turkish adult population. Depress Anxiety. 2008;25(10):E104-10. doi: 10.1002/da.20371.

23. VanVoorhis CRW, Blumentritt TL. Psychometric properties of the Beck Depression Inventory-II in a clinically-identified sample of Mexican American adolescents. J Child Fam Stud. 2007;16(6):789-98. doi: 10.1007/s10826-006-9125-y.

24. Hirschfeld RM, Williams JB, Spitzer RL, Calabrese JR, Flynn L, Keck PE, Jr., et al. Development and validation of a screening instrument for bipolar spectrum disorder: the Mood Disorder Questionnaire. Am J Psychiatry. 2000;157(11):1873-5. doi: 10.1176/appi.ajp.157.11.1873.

25. 25. Masaeli N, Afshar H, Molavi H, Malekiyan A, Barekatain M. Psychometric properties of the Mood Disorder Questionnaire in Isfahan, Iran. Journal of Research in Behavioural Sciences. 2012;10(4):250-257. [Persian]

26. Bakker D, Kazantzis N, Rickwood D, Rickard N. Development and Pilot Evaluation of Smartphone-Delivered Cognitive Behavior Therapy Strategies for Mood- and Anxiety-Related Problems: MoodMission. Cogn Behav Pract. 2018;25(4):496-
514. doi: 10.1016/j.cbpra.2018.07.002.

27. Lovas DA, Schuman-Olivier Z. Mindfulness-based cognitive therapy for bipolar disorder: A systematic review. J Affect Disord. 2018;240:247-61. doi: 10.1016/j.jad.2018.06.017.

28. Tanoue $\mathrm{H}$, Yoshinaga $\mathrm{N}$, Kato S, Naono-Nagatomo K, Ishida Y, Shiraishi Y. Nurse-led group cognitive behavioral therapy for major depressive disorder among adults in Japan: A preliminary single-group study. Int J Nurs Sci. 2018;5(3):21822. doi: 10.1016/j.ijnss.2018.06.005.

29. Soltanizadeh M. Comparison of the effectiveness of cognitivebehavioral, meta-cognitive-behavioral therapy and mindfocused therapy on early ejaculation, marital satisfaction, anxiety, and depression in men referred to Isfahan health centers [Thesis]. Isfahan: University of Esfahan; 2012. [Persian]

30. Ghamari H, Dastani S, Ghadimi S. The effectiveness of Cognitive Behavioral Therapy on reducing depression and ruminants in women with chronic fatigue syndrome. Quarterly Journal of Research Advisory. 2015;13(50):101-18. [Persian]

31. Mansouri S. Effectiveness of harm-based cognitive-behavioral therapy on reducing depression, anxiety, and shame and increasing the support of parents of adolescents victims of sexual abuse in Ahvaz city [Thesis]. Ahvaz: Shahid Chamran University of Ahvaz; 2015. [Persian]

32. Molavi SH. Study of cognitive-behavioral and interpersonal therapies in reducing depression, increasing marital satisfaction and perceived social support in women with postpartum depression in one of the midwifery offices of Ahvaz [Thesis]. Ahvaz: Shahid Chamran University of Ahvaz; 2014. [Persian]

33. Pleger M, Treppner K, Diefenbacher A, Schade C, Dambacher C, Fydrich T. Effectiveness of Acceptance and Commitment Therapy compared to $\mathrm{CBT}+$ : Preliminary results. Eur J Psychiatry. 2018;32(4):166-73. doi: 10.1016/j. ejpsy.2018.03.003.

34. Twohig MP, Levin ME. Acceptance and Commitment Therapy as a Treatment for Anxiety and Depression: A Review. Psychiatr Clin North Am. 2017;40(4):751-70. doi: 10.1016/j. psc.2017.08.009.

35. Moharami J. Effect of Cognitive-behavioral Therapy and Acceptance and Commitment Therapy on depression symptoms [Thesis]. Ardabil: Mohaghegh Ardabili University; 2016. [Persian]

36. Hor M, Aghaei A, Abedi A, Attari A. The effectiveness of acceptance and commitment therapy on depression in patients with type 2 diabetes. Journal of Research in Behavioural Sciences. 2013;11(2):121-8. 